\title{
Increased Vitronectin Production by Complement- Stimulated Human Retinal Pigment Epithelial Cells
}

\author{
Susanne Wasmuth, ${ }^{1}$ Katharina Lueck, ${ }^{1}$ Hanna Baebler, ${ }^{1}$ Albrecht Lommatzsch, ${ }^{1}$ and \\ Daniel Pauleikhoff ${ }^{1,2}$
}

Purpose. A variation in the complement factor $\mathrm{H}$ gene was associated with an enhanced risk to develop especially early age-related macular degeneration. Drusen and basal laminar deposits are hallmarks of this AMD manifestation that contain vitronectin as a major component. In this study, the correlation between complement stimulation and vitronectin production of retinal pigment epithelial (RPE) cells was investigated.

Methods. ARPE-19 cells, a permanent cell line of human RPE cells, were supplemented with and without human complement competent serum in medium with and without heat inactivated fetal calf serum. The cells were examined in situ for their vitronectin production as an effective inhibitor of alternatively activated complement by immunohistochemistry. Semi-quantitative RT-PCR and Western blots were performed to analyze vitronectin mRNA and protein.

REsults. A strong immunohistochemical staining for vitronectin was observed after complement supplementation. The enhanced production of this complement inactivator by ARPE-19 cells was confirmed by Western blot, whereas the expression analysis revealed unaltered mRNA amounts.

Conclusions. A stimulation of RPE cells with complement resulted in an upregulated production of vitronectin. This may support the concept of a protective mechanism, since vitronectin is the major inhibitor of complement activated by the alternative pathway. On the other hand, this increased vitronectin production after complement stimulation may contribute to focal or diffuse deposits in Bruch's membrane, as observed in early AMD. (Invest Ophthalmol Vis Sci. 2009;50: 5304-5309) DOI:10.1167/iovs.08-3326

$\mathrm{T}$ he complement system is part of the innate immunity and provides first-line defense against a variety of pathogens, such as helminths or bacteria. The activation of the complement cascade is potentially harmful for the host's own cells, therefore it is strictly regulated. A mutation in the gene encoding for complement factor $\mathrm{H}(\mathrm{CFH})$ that leads to a less active inhibition of the alternative pathway was proven to be strongly related to the development of age-related macular degenera-

From the ${ }^{1}$ Department of Ophthalmology, St. Franziskus Hospital, Ophtha-Lab, Muenster, Germany; and the ${ }^{2}$ Department of Ophthalmology, University Duisburg-Essen, Essen, Germany.

Supported by Voltmann Foundation and Akademie des Sehens.

Submitted for publication December 17, 2008; revised March 13, 2009; accepted August 25, 2009.

Disclosure: S. Wasmuth, None; K. Lueck, None; H. Baehler, None; A. Lommatzsch, None; D. Pauleikhoff, None

The publication costs of this article were defrayed in part by page charge payment. This article must therefore be marked "advertise$m e n t "$ in accordance with 18 U.S.C. $\$ 1734$ solely to indicate this fact.

Corresponding author: Daniel Pauleikhoff, Augenärzte am St. Franziskus Hospital, Hohenzollernring 74, 48145 Muenster, Germany; dapauleikhoff@muenster.de. tion (AMD). ${ }^{1-4}$ These findings about CFH suggested a role for activated complement in the pathogenesis of AMD, although the precise involvement of CFH in the development of AMD is unknown. ${ }^{5}$ Further protective alleles have been identified in the genes coding for factor $\mathrm{B}$ and complement component $2,{ }^{6,7}$ and a functional polymorphism in the complement component 3 gene in relation to AMD was also described. ${ }^{8}$ Especially in early AMD, an increased activation of complement might play an important role. ${ }^{9,10}$

Throughout life, the accumulation of debris results in changes of Bruchs' membrane (BrM) characterized by a deposition of lipids and an abnormal composition of extracellular matrix proteins. ${ }^{11}$ This process may result in the development of focal or diffuse deposits in BrM known as drusen or basal laminar and linear deposits (BLD), which are histopathological hallmarks for AMD. ${ }^{12,13}$ Drusen and BLD showed positive staining for vitronectin ${ }^{14,15}$; also, the cytoplasm of RPE cells in close proximity to drusen was immunoreactive for antibodies recognizing vitronectin. ${ }^{16}$ In addition, drusen were shown to contain the membrane attacking complex (MAC) also termed $\mathrm{C} 5 \mathrm{~b}-9$, the final product of activated complement. ${ }^{17,18}$ An enhanced staining for vitronectin was also detected in BLD of removed choroidal neovascular membranes of AMD patients. ${ }^{19,20}$ The source of vitronectin and the corresponding mRNA could be RPE cells ${ }^{14,21}$ and the photoreceptor cells. $^{22}$

In atherosclerosis, a disease with some similarities to AMD, vitronectin was interpreted as an important mediator of disease. ${ }^{23-25}$ Atherosclerotic deposits also contain vitronectin and the MAC as indicated by positive staining for S-Protein and C $5 \mathrm{~b}-9,{ }^{26}$ and the vitronectin deposition is thought to be initiated to inhibit complement.

Vitronectin or S-Protein is an acidic glycoprotein that can bind to the C5b-9 complex in free solution and thereby has a protective effect by preventing the attachment of the complex to the surface of cells. ${ }^{27}$ In particular, the metastable membrane-binding site of the nascent precursor complex C5b-7 is occupied by vitronectin ${ }^{28}$ and it inhibits the polymerization of C9 in a concentration dependant manner. ${ }^{29}$

The degeneration of the RPE and other abnormalities of these cells were closely connected to AMD. ${ }^{30,31}$ The present study was conducted to clarify whether complement can alter directly the vitronectin production of RPE cells. Therefore, cells of the well-established adherent human retinal pigment epithelial cell line ARPE- $19^{32}$ were used as model for RPE metabolism. To investigate if the vitronectin production by RPE cells is enhanced by complement, the cells were challenged with different complement preparations in vitro and their production of vitronectin was confirmed by immunohistochemistry, mRNA analysis, and Western blot.

\section{Material ANd Methods}

\section{Cell Culture}

ARPE-19 cells (ATCC number CRL-2302) were grown in T75 flasks (Nunc, Rochester, NY) and cultured in a 1:1 mixture of DMEM and 
TABLE 1. Sequences of the Primers Used in this Study, the Annealing Temperatures in the PCR Protocols, and the Lengths of the Specific Amplification Products

\begin{tabular}{llll}
\hline \multicolumn{1}{c}{ Product } & Primer & \multicolumn{1}{c}{ Sequence from 5' to $\mathbf{3}^{\prime}$} & $\begin{array}{c}\text { Annealing Temperature/ } \\
\text { Product Size }\end{array}$ \\
\hline Vitronectin 1 & Forward & CGA GGA GAA AAA CAA TGC CAC & $58.1^{\circ} \mathrm{C} / 502 \mathrm{bp}$ \\
Vitronectin 2 & Reverse & GAA GCC GTC AGA GAT ATT TCG & \\
& Forward & CCT TCA CCG ACC TCA AGA AC & $56.6^{\circ} \mathrm{C} / 257 \mathrm{bp}$ \\
GAPDH & Reverse & GAA GCC GTC AGA GAT ATT TCG & $54.7^{\circ} \mathrm{C} / 177 \mathrm{bp}$ \\
& Forward & ATG ACA TCA AGA AGG TGG TG & \\
\hline
\end{tabular}

Ham's F12 (Biochrom, Berlin, Germany) containing 15 mM HEPES, 2.5 $\mathrm{mM}$ glutamine, $1.2 \mathrm{~g} / \mathrm{L}$ sodium bicarbonate, and $0.5 \mathrm{mM}$ sodium pyruvate. The medium was supplemented with penicillin and streptomycin (PAA, Pasching, Austria) and 10\% heat inactivated fetal calf serum (FCS; Biochrom). For subcultivation that was necessary every 7 to 10 days, the adherent cells were detached by trypsin-EDTA solution (PAA) and split in a 1 to 5 ratio. In running cultures the medium was renewed 2 to 3 times a week.

\section{Study Design}

The RPE cells were grown in eight-well chamber slides (BD Biosciences Europe, Erembodegem, Belgium) for immunohistochemistry and in six-well plates for protein and RNA extraction in DMEM/F12 containing $10 \%$ FCS. They were allowed to adhere overnight, were washed twice with phosphate buffered saline (PBS) and supplemented with fresh media alone with and without FCS or media containing 1, 5, and $10 \mu \mathrm{g}$ lipopolysaccharide (LPS)/mL (from Escherichia coli, Sigma, Taufkirchen, Germany). LPS treated cells were used as control for ARPE-19 cells activated by a stimulus unrelated to complement. In other sets of experiments 1,5 , and $10 \mu \mathrm{L}$ of complement (human complement sera, 74 or 51 CH50 Units/mL, Sigma) per $250 \mu \mathrm{L}$ medium were added. All incubations were done for 24 hours. A second source of human complement competent serum was gained by venous puncture without any anticoagulants. This preparation underwent the natural blood clotting process at room temperature and was centrifuged 30 minutes later for 10 minutes at $1800 \mathrm{~g}$. One half of the batch was heat-inactivated for 30 minutes at $56^{\circ} \mathrm{C}$ and naive and heat-inactivated serum was stored in aliquots at $-80^{\circ} \mathrm{C}$. This second complement source was examined at concentrations of $1 \%, 5 \%$, and $10 \%$. In some experiments zymosan A (Sigma), an activator of both the alternative and the classic complement pathway, ${ }^{33}$ was included. Zymosan was tested alone and in combination with complement competent serum; the concentration was $0.5 \mathrm{mg}$ per $100 \mu \mathrm{L}$ serum, as published previously by others. ${ }^{34}$

\section{Immunohistochemistry}

ARPE-19 cells were cultured in eight-well chamber slides (Becton Dickinson, Heidelberg, Germany) near to confluency. They were washed twice with PBS and were fixed for 10 minutes in $4 \%$ buffered formaldehyde. After additional washing steps with PBS, a monoclonal mouse anti-human vitronectin antibody (TaKaRa, Saint-Germain-enLaye, France) was incubated at a concentration of $5 \mu \mathrm{g} / \mathrm{mL}$ in PBS containing $5 \%$ fetal calf serum for 1 hour at room temperature. The cells in the chamber slides were washed with tris-buffered saline (TBS) and $100 \mu \mathrm{L}$ universal link (DAKO, Glostrup, Denmark) was added for 15 minutes, followed by washing with TBS and 15 minutes incubation with alkaline phosphatase conjugated to streptavidin (DAKO). The red reaction product was developed by fuchsin substrate in 20 to 30 minutes, and Gill No. 3 (Sigma) was used as a blue counterstaining. After washing with distilled water, the blue color was fixed with ammonium water and the cells were coverslipped with aquatex (Merck, Darmstadt, Germany) after two additional washing steps with distilled water.

\section{RNA Analysis}

Total RNA of $1 \times 10^{6}$ ARPE-19 incubated 24 hours with the different stimuli in serum-free and serum-containing media was extracted by an extraction kit (RNeasy; Qiagen, Hilden, Germany) as recommend by the supplier. First strand cDNA synthesis of $1 \mu \mathrm{g}$ of RNA of each specimen was performed by reverse transcription kit (Omniscript; Qiagen) according to the protocol of the manufacturer. Control reactions run without any mRNA template. Adjacent PCR with Taq polymerase (HotStar; Qiagen) started with an initial denaturating step at $95^{\circ} \mathrm{C}$ for 15 minutes followed by 30 cycles (for GAPDH) or 35 cycles (for vitronectin), each consisting of 30 seconds at $94^{\circ} \mathrm{C}, 30$ seconds annealing temperature, and 1 minute at $72^{\circ} \mathrm{C}$ for the extension followed by a terminal 10 -minute extension phase at $72^{\circ} \mathrm{C}$. The PCR products were examined on $1.8 \%$ agarose gels and the obtained bands were analyzed by ImageJ (NIH freeware; developed by Wayne Rasband, National Institutes of Health, Bethesda, MD; available at http:// rsb.info.nih.gov/ij). Two different primer pairs specific for human vitronectin published elsewhere ${ }^{22}$ were used, and GAPDH expression (primer design by Teresa Hsi, Harvard NeuroDiscovery Center, Boston, MA) was investigated as housekeeping gene (see Table 1 for the sequences of the primers). All primer pairs span two exons and were specific for human cDNA.

\section{Protein Isolation}

Total protein of $1 \times 10^{6}$ ARPE-19 incubated 24 hours with the different stimuli in serum-free and serum-containing media was isolated according to a standard protocol. Briefly, the cells were washed twice with PBS, detached mechanically with ice-cold PBS and a cell scraper and were pelleted by centrifugation. The cell pellet was resuspended in pre-cooled RIPA buffer ( $2 \%$ nonidet-P40, $50 \mathrm{mM}$ Tris-HCl, $150 \mathrm{mM}$ sodium chloride, $1 \mathrm{mM}$ EDTA, $0.5 \%$ sodium desoxycholate, $0.1 \%$ sodium dodecylsulfate, $1 \mathrm{mM}$ sodium orthovanadate, $1 \mathrm{mM}$ phenylmethane-sulfonyl fluoride, $10 \mu \mathrm{g} / \mathrm{mL}$ leupeptin and $10 \mu \mathrm{g} / \mathrm{mL}$ pepstatin adjusted to $\mathrm{pH} 7.4$ ) and sonicated on ice. After centrifugation at $14,000 \mathrm{~g}$, the soluble protein was aliquoted and frozen at $-20^{\circ} \mathrm{C}$. The protein concentration was analyzed by protein assay kit (DC Protein Assay kit; Bio-Rad Laboratories, Munich, Germany) before usage in downstream applications.

\section{Western Blot}

First, $10 \mu \mathrm{g}$ of protein was applied in each lane of two identical $10 \%$ polyacrylamide minigels and electrophoresis was done for 3 hours and $120 \mathrm{~V}$ at $4^{\circ} \mathrm{C}$. Negative controls were performed without any protein, a positive control with proteins extracted from human serum run on each gel. A prestained protein standard (Santa Cruz Biotechnology, Santa Cruz, CA) was used to estimate the molecular weight of the obtained bands. One gel was stained by Coomassie blue, the other one was blotted on nitrocellulose membrane (Roth, Karlsruhe, Germany) for 45 minutes at $350 \mathrm{~mA}$. The blots were saturated with TBS containing $0.5 \%$ Tween 20 and 3\% bovine serum albumin (BSA) over night at $4^{\circ} \mathrm{C}$. The blot was incubated for 3 hours with the vitronectin-specific antibody (TaKaRa) diluted 1:2000 in TBS containing 0.5\% Tween 20 and 1\% BSA. After washing with TBS and 0.5\% Tween 20, 1:3000 


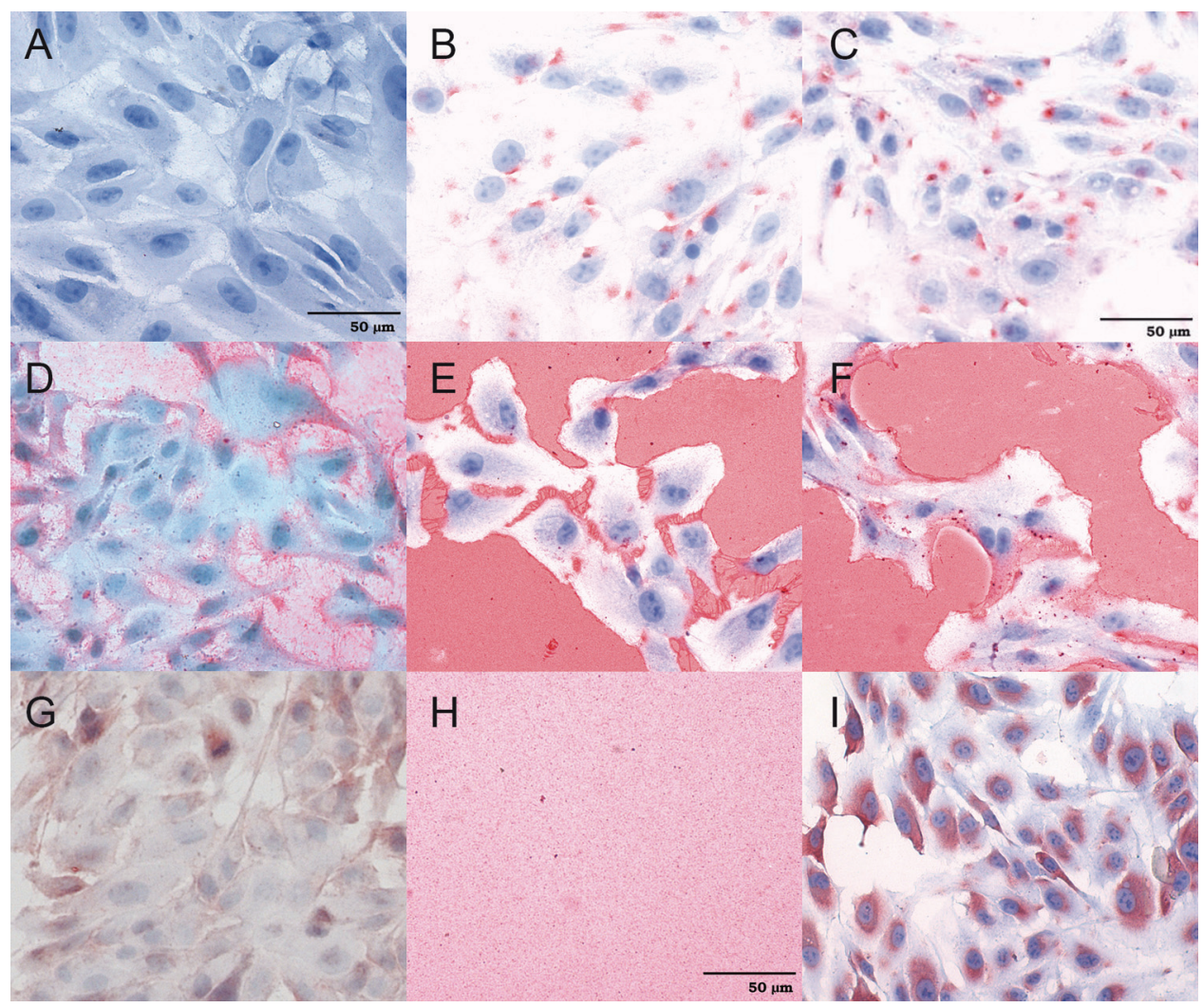

FIGURE 1. Immunohistochemistry staining of vitronectin expression (red) by ARPE-19 cells in serum-free medium in response to complement. (A) Cells of the isotype controls for immunohistochemistry showed no vitronectin-specific staining. (B) Untreated ARPE-19 cells showed no or only a light spotted staining for vitronectin. (C) Only marginal to no enhanced spotted vitronectin staining occurred after the addition of zymosan A with no background. (D) The supplementation with $0.05 \mathrm{CH} 50$ $\mathrm{U} / \mathrm{mL}$ human complement serum lead to a strongly enhanced staining for vitronectin. (E) With $5 \mathrm{CH} 50 \mathrm{U} / \mathrm{mL}$ this positive staining further increased. (F) Strong evidence occurs for vitronectin after the combination of zymosan A with human complement serum and staining of the cell culture vessel bottom. (G) Staining of ARPE-19 cells supplemented with $10 \mu \mathrm{g}$ LPS/mL gave a light signal but revealed no background staining. (H) In this view, $5 \mathrm{CH} 50 \mathrm{U} / \mathrm{mL}$ human complement serum without any cells gave a background staining for vitronectin with an intensity not that strong as observed in the presence of RPE cells. (I) In FCS containing medium a vitronectinspecific staining around the nucleus without any background staining was detected.

diluted biotinylated rabbit anti-mouse IgG $\mathrm{F}\left(\mathrm{ab}^{\prime}\right)_{2}$ fragments (DAKO) as secondary antibodies were applied on the blot for 45 minutes. After washing, the membrane was incubated for 20 minutes with 1:4000 diluted horseradish peroxidase conjugated to streptavidin (DAKO). The blots were thoroughly rinsed before they were wrapped with plastic film and covered with an x-ray film (X-OMAT AR; Kodak, Stuttgart, Germany). The chemoluminescent detection of the bands was performed by addition of luminol (Santa Cruz Biotechnology). The density of the bands was analyzed by ImageJ and the statistical analyses of the data were done by statistical software (SPSS; SPSS Inc., Chicago, IL).

\section{Results}

Vitronectin was constitutively expressed at low levels by cultured ARPE-19 cells (Fig. 1B) but was not detected in isotype and negative controls (Fig. 1A). When human complement competent serum was added to the serum-free media, the immunohistochemical staining for vitronectin was strongly enhanced in a concentration dependent manner (Figs. 1D, 1E). Additionally, increased cell detachment during the staining procedure was observed with increasing concentrations of complement. The cells themselves were stained mainly at their borders, and a strong labeling of the surrounding matrix was observed. The same results were obtained when the cells were cultured in serum-containing medium, although the staining intensity for vitronectin was decreased. When ARPE-19 cells were stimulated with LPS, no enhanced staining for vitronectin either of the surrounding matrix or of the cells was detected. Only at the highest concentration of $10 \mu \mathrm{g} / \mathrm{mL}$ tested was some staining of the cytoplasma around the nucleus noted (Fig. 1G). Comparable vitronectin specific staining was found in ARPE-19 cells that were cultured in FCS containing medium (Fig. 1I), but the staining in LPS and FCS treated cells was in clear difference to the findings of a strong positive staining result for vitronectin after complement addition (compare Figs.
$1 G$ and 1 I to $1 \mathrm{D}$ and $1 \mathrm{E})$. ARPE-19 cells incubated with zymosan showed only a very slight enhanced spotted staining for vitronectin (Fig. 1C). In contrast, the combination of zymosan and human complement competent serum gave a strong positive signal (Fig. 1F).

To clarify whether the vitronectin staining was due to a release of that extracellular matrix protein by ARPE-19 cells into the surrounding environment or due to a possible vitronectin contamination by the serum used as a source of complement, slides without any cells were stained. A red background staining of the cell culture vessel bottom with human complement serum independent of its source was detected (Fig. $1 \mathrm{H}$ ), although the staining intensity was lower than in specimens including RPE cells. No background was detected when LPS or zymosan were added alone to the medium and incubated for 24 hours on the slides. These findings were independent of the presence or absence of FCS.

When cDNA obtained from total RNA of ARPE-19 cells that were incubated with increasing concentrations of complement serum was analyzed by PCR, no differences in GAPDH expression were detected (Fig. 2A). Also, no enhanced detection of PCR products specific for vitronectin were measured (Fig. 2B). The same results were obtained with both vitronectin specific primer pairs. This was also found in densitometry analysis of the respective bands (Fig. 2C).

To verify that the enhanced vitronectin observed in immunohistochemistry after incubation with complement serum stem from the RPE cells themselves, we isolated total protein of untreated ARPE-19 cells and those treated with human complement serum. In SDS gels of cells incubated with human complement competent serum, a band of approximately 75 $\mathrm{kDa}$ was clearly stronger (Fig. 3A). When protein lysates of human liver cells as known vitronectin producers were examined, the detected band for vitronectin was on the same heights, indicating the same molecular weight of approximately $75 \mathrm{kDa}$. Further analysis in Western blot experiments 


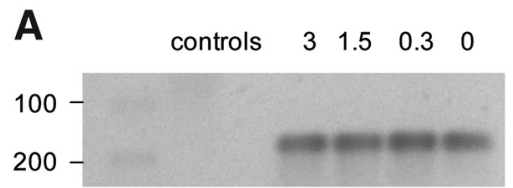

B
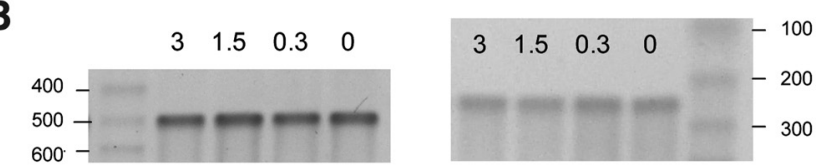

vitronectin 502 bp vitronectin $257 \mathrm{bp}$

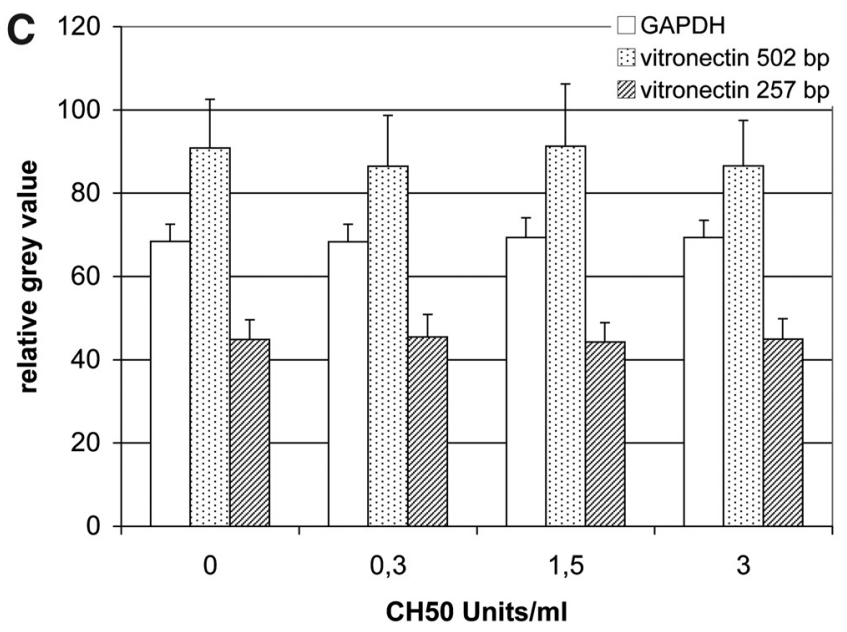

FigURE 2. PCR analysis of cDNA gained by total RNA isolated from human complement serum treated RPE cells in the same concentrations as tested in the immunohistochemistry. (A) PCR products showing evenly bands for GAPDH as house keeping gene that did not differ between the four experimental groups with the various $\mathrm{CH} 50 \mathrm{U} / \mathrm{mL}$. (B) The same was found for the vitronectin specific products produced by both primer pairs. (C) No alterations of the relative vitronectin expression were observed by densitometry analysis of the obtained bands in the agarose gels.

confirmed that a band corresponding to vitronectin was detected constitutively in proteins extracted from untreated ARPE-19 cells and that this band was stronger in protein preparations isolated from complement serum treated RPE cells (Fig. 3B). Densitometry analysis indicated a 1.2 to 1.7 -fold increase in vitronectin protein production by RPE cells evoked by complement serum (Fig. 3C).

\section{Discussion}

Genetic studies demonstrated the involvement of a variant in the complement factor $\mathrm{H}$ gene that will allow an increased activation of the complement system via the alternative pathway during the development of AMD. In particular, BrM deposits of early AMD patients like drusen and BLD were suspected to be triggered by complement or to trigger complement activation via the alternative pathway. The predominant extracellular matrix component of these deposits is vitronectin. Therefore, the theory arose that vitronectin production by RPE cells might be the result of a protective mechanism against the attack by activated complement. ${ }^{19,20}$ The findings of the present study supported this hypothesis and
A

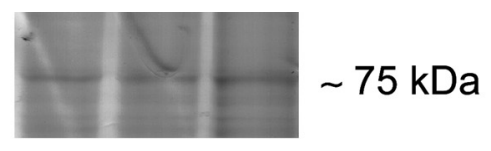

$\begin{array}{lll}0 & 1 & 2\end{array}$

$\mathrm{CH} 50 \mathrm{U} / \mathrm{ml}$

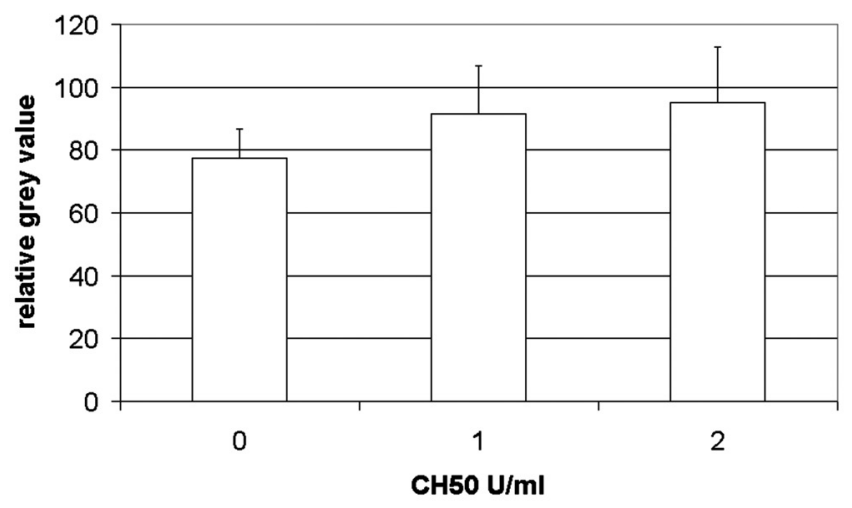

B

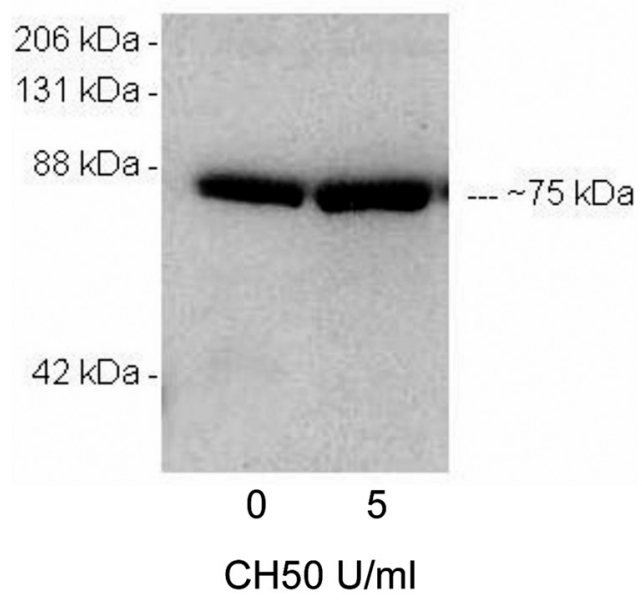

C

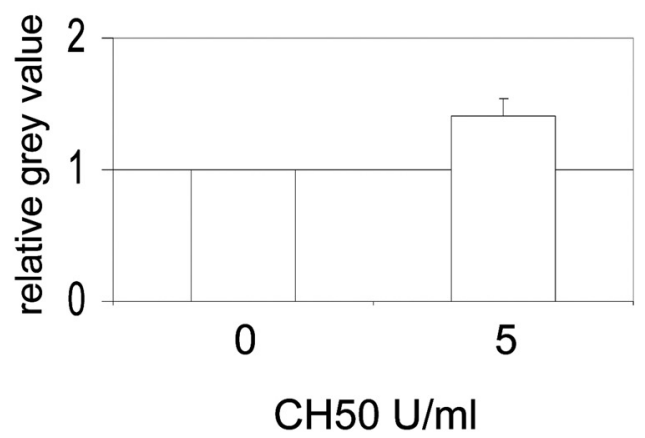

FiguRE 3. Analysis of protein extracted from ARPE-19 cells grown in serum-free medium. (A) Coomassie stained SDS gel of untreated (lane 2) and complement serum treated (lane 3) cells showing a thicker band at approximately $75 \mathrm{kDa}$ in the cells treated with complement serum. (B) A typical result of a Western blot experiment with an upregulation of the vitronectin-specific band in complement treated RPE cells. (C) Densitometry of seven independent performed Western blots confirmed a significantly enhanced production of vitronectin after incubation with complement serum $(P<0.05)$. The $95 \%$ confidence interval was 1.29-1.53 and the SD is shown as an error bar. 
gave evidence that complement can trigger RPE cells to produce vitronectin.

ARPE-19 cells cultured on BrM from aged donors showed diminished gene expression for vitronectin when compared to culturing on BrM explants from younger donors. ${ }^{35}$ Given this in combination with a protective function of vitronectin against activated complement and the results of our study, this may suggest that an enhanced production of vitronectin by RPE cells after complement challenge may reflect a defense mechanism with bystander deposition of vitronectin under the RPE. In vivo, this process might support the development of drusen, BLD, and later, AMD. ARPE-19 cells from Larry M. Hjelmeland (University of California, Davis, CA) were heterozygous for the $\mathrm{Y} 402 \mathrm{H}$ polymorphism, as revealed by SNP analysis (Lincoln V. Johnson, personal communication, February 2008). Thereby, these cells possess the genotype of persons with an enhanced risk for developing AMD, although the homozygous genotype is even more endangered.

Vitronectin occurs as a component of the extracellular matrix and also as soluble form in serum. Indeed, we found a vitronectin-specific background staining in human complement serum preparations. This background staining was not that strong, as observed in the immunohistochemistries that included RPE cells, yet it was initially not clear if the observed enhanced detection of vitronectin was produced by the RPE cells themselves.

To further confirm the vitronectin production by RPE cells after incubation with complement serum, we performed RTPCR. With both primer pairs we did not detect any upregulation of vitronectin. This indicates that the enhanced production of vitronectin by RPE cells after incubation with complement serum is not regulated by de novo synthesis of mRNA transcripts and might include other mechanisms such as prolonged half-life of mRNA.

Additional Western blots with protein isolations from complement treated and untreated cells clearly showed that at least in part the detected vitronectin proteins were expressed in enhanced amounts by the cells. Therefore, RPE cells were identified as an important source for vitronectin after incubation with complement serum. That RPE cells are producers of vitronectin is in accordance with previously published results. ${ }^{14}$ Hepatocytes were described as the cells with the highest production of vitronectin. ${ }^{36}$ In our study, the vitronectin production of RPE cells exceeded those of hepatocytes, as detected by direct comparison of protein preparations from human liver and from ARPE-19 cells. For vitronectin, different molecular weights were shown: while vitronectin proteins from serum are $80 \mathrm{kDa}$ and $70 \mathrm{kDa}$, a single chain molecule with a molecular weight of 75 to $78 \mathrm{kDa}$ is produced by hepatocytes. ${ }^{37}$ In addition, a two-chain form of $65+10 \mathrm{kDa}$ resulting in $75 \mathrm{kDa}$ and with the occurrence in the circulation is known. ${ }^{38}$ We observed a molecular weight of $75 \mathrm{kDa}$ for the vitronectin produced by the ARPE-19 cells. Supplementary experiments should clarify if this corresponds to the single chain or the two-chain form of vitronectin.

The induced vitronectin production by RPE cells by complement can be viewed as a sign for the activation of these cells. Activated $\mathrm{T}$ cells can also stimulate RPE cells to an upregulation of complement factors and enhance the vitronectin response approximately 1.5 -fold (Juel H, et al. IOVS 2008; 49:ARVO E-Abstract 5152). This might suggest an increased production of vitronectin by RPE cells as a specific reaction on complement that is not observed after a stimulus like LPS.

There is the possibility that ARPE-19 cells as a permanent cell line do not closely simulate the behavior of in vivo RPE cells in the eye. Therefore, one future goal is to repeat the experiments with primary cultures of RPE cells and to examine confluent monolayers grown on filter inserts to mimic the in vivo situation more closely.

Taken together, this study showed that RPE cells can be stimulated to produce an important regulatory protein of the alternative pathway of complement activation in reaction to human complement serum. This may mirror a protective mechanism to inactivate the complement cascade on the one hand, but on the other hand, may promote in vivo focal deposits as drusen or diffuse laminar and linear deposits in $\mathrm{BrM}$, as observed in early AMD. The enhanced production of vitronectin by RPE cells after complement exposure might explain at least in part the underlying mechanism with which complement can contribute to the development of early AMD.

\section{Acknowledgments}

The authors thank Martin Busch for his assistance with statistical software (SPSS; SPSS Inc.).

\section{References}

1. Edwards AO, Ritter R 3rd, Abel KJ, et al. Complement factor $\mathrm{H}$ polymorphism and age-related macular degeneration. Science. 2005;308:421- 424 .

2. Hageman GS, Anderson DH, Johnson LV, et al. A common haplotype in the complement regulatory gene factor $\mathrm{H}(\mathrm{HF} 1 / \mathrm{CFH})$ predisposes individuals to age-related macular degeneration. Proc Natl Acad Sci US A. 2005;102:7227-7232.

3. Haines JL, Hauser MA, Schmidt S, et al. Complement factor $\mathbf{H}$ variant increases the risk of age-related macular degeneration. Science. 2005;308:419-421.

4. Klein RJ, Zeiss C, Chew EY, et al. Complement factor $\mathrm{H}$ polymorphism in age-related macular degeneration. Science. 2005;308: 385-389.

5. Sivaprasad S, Chong NV. The complement system and age-related macular degeneration. Eye. 2006;20:867-872.

6. Gold B, Merriam JE, Zernant J, et al. Variation in factor B (BF) and complement component 2 (C2) genes is associated with agerelated macular degeneration. Nat Genet. 2006;38:458-462.

7. Spencer KL, Hauser MA, Olson LM, et al. Protective effect of complement factor B and complement component 2 variants in age-related macular degeneration. Hum Mol Genet. 2007;16: 1986-1992.

8. Yates JR, Sepp T, Matharu BK, et al. Complement C3 variant and the risk of age-related macular degeneration. New Engl J Med. 2007;357:553-561.

9. Despriet DD, Klaver CC, Witteman JC, et al. Complement factor $\mathrm{H}$ polymorphism, complement activators, and risk of age-related macular degeneration. JAMA. 2006;296:301-309.

10. Schaumberg DA, Christen WG, Kozlowski P, Miller DT, Ridker PM, Zee RY. A prospective assessment of the $\mathrm{Y} 402 \mathrm{H}$ variant in complement factor $\mathrm{H}$, genetic variants in $\mathrm{C}$-reactive protein, and risk of age-related macular degeneration. Invest Opbthalmol Vis Sci. 2006; $47: 2336-2340$

11. Zarbin MA. Age-related macular degeneration: review of pathogenesis. Eur J Ophthalmol. 1998;8:199-206.

12. Pauleikhoff D. [Drusen in Bruch's membrane. Their significance for the pathogenesis and therapy of age-associated macular degeneration]. Ophthalmologe. 1992;89:363-386.

13. Pauleikhoff D, Chen J, Bird AC, Wessing A. [The Bruch membrane and choroid. Angiography and functional characteristics in agerelated changes]. Opbthalmologe. 1992;89:39-44.

14. Hageman GS, Mullins RF, Russell SR, Johnson LV, Anderson DH. Vitronectin is a constituent of ocular drusen and the vitronectin gene is expressed in human retinal pigmented epithelial cells. FASEB J. 1999;13:477-484.

15. Russell SR, Mullins RF, Schneider BL, Hageman GS. Location, substructure, and composition of basal laminar drusen compared with drusen associated with aging and age-related macular degeneration. Am J Opbthalmol. 2000;129:205-214.

16. Johnson LV, Leitner WP, Staples MK, Anderson DH. Complement activation and inflammatory processes in Drusen formation and age related macular degeneration. Exp Eye Res. 2001;73:887-896. 
17. Mullins RF, Russell SR, Anderson DH, Hageman GS. Drusen associated with aging and age-related macular degeneration contain proteins common to extracellular deposits associated with atherosclerosis, elastosis, amyloidosis, and dense deposit disease. FASEB J. 2000;14:835-846.

18. Johnson LV, Ozaki S, Staples MK, Erickson PA, Anderson DH. A potential role for immune complex pathogenesis in drusen formation. Exp Eye Res. 2000;70:441-449.

19. Pauleikhoff D. Neovascular age-related macular degeneration: natural history and treatment outcomes. Retina. 2005;25:1065-1084.

20. Lommatzsch A, Hermans P, Weber B, Pauleikhoff D. Complement factor $\mathrm{H}$ variant $\mathrm{Y} 402 \mathrm{H}$ and basal laminar deposits in exudative age-related macular degeneration. Graefes Arch Clin Exp Opbthalmol. 2007;245:1713-1716.

21. Ozaki S, Johnson LV, Mullins RF, Hageman GS, Anderson DH. The human retina and retinal pigment epithelium are abundant sources of vitronectin mRNA. Biochem Biophys Res Comm. 1999;258: 524-529.

22. Anderson DH, Hageman GS, Mullins RF, et al. Vitronectin gene expression in the adult human retina. Invest Ophthalmol Vis Sci. 1999; 40:3305-3315.

23. Ekmekci OB, Ekmekci H. Vitronectin in atherosclerotic disease. Clin Cbim Acta. 2006;368:77-83.

24. Rus H, Niculescu F. Association of complement inhibitors with connective tissue matrix in atherosclerotic lesions. Arterioscler Thromb Vasc Biol. 2003;23:1478.

25. Niculescu F, Rus HG, Vlaicu R. Activation of the human terminal complement pathway in atherosclerosis. Clin Immunol Immunopatbol. 1987;45:147-155.

26. Niculescu F, Rus HG, Vlaicu R. Immunohistochemical localization of C5b-9, S-protein, C3d and apolipoprotein B in human arterial tissues with atherosclerosis. Atherosclerosis. 1987;65:1-11.

27. Podack ER, Muller-Eberhard HJ. Isolation of human S-protein, an inhibitor of the membrane attack complex of complement. Journal Biol Chem. 1979;254:9808-9814.

28. Preissner KT, Podack ER, Muller-Eberhard HJ. The membrane attack complex of complement: relation of $\mathrm{C} 7$ to the metastable membrane binding site of the intermediate complex C5b-7. J Immunol. 1985;135:445-451.

29. Podack ER, Preissner KT, Muller-Eberhard HJ. Inhibition of C9 polymerization within the SC5b-9 complex of complement by S-protein. Acta Patbol, Microbiol Immunol Scand. 1984;284:8996.

30. Lewis H, Straatsma BR, Foos RY, Lightfoot DO. Reticular degeneration of the pigment epithelium. Opbthalmology. 1985;92:14851495 .

31. Bressler NM, Munoz B, Maguire MG, et al. Five-year incidence and disappearance of drusen and retinal pigment epithelial abnormalities. Waterman study. Arch Ophthalmol. 1995;113:301-308.

32. Dunn KC, Aotaki-Keen AE, Putkey FR, Hjelmeland LM. ARPE-19, a human retinal pigment epithelial cell line with differentiated properties. Exp Eye Res. 1996;62:155-169.

33. Glovsky MM, Cortes-Haendchen L, Ghekiere L, Alenty A, Williams DL, Di Luzio R. Effects of particulate beta-1,3 glucan on human, rat, and guinea pig complement activity. J Reticuloendothel Soc. 1983; 33:401-413.

34. Zhou J, Jang YP, Kim SR, Sparrow JR. Complement activation by photooxidation products of A2E, a lipofuscin constituent of the retinal pigment epithelium. Proc Natl Acad Sci US A. 2006;103: 16182-16187.

35. Cai H, Del Priore LV. Bruch membrane aging alters the gene expression profile of human retinal pigment epithelium. Curr Eye Res. 2006;31:181-189.

36. Seiffert D, Keeton M, Eguchi Y, Sawdey M, Loskutoff DJ. Detection of vitronectin mRNA in tissues and cells of the mouse. Proc Natl Acad Sci U S A. 1991;88:9402-9406.

37. Neumeier R, Reutter W. Hepatocyte adhesion on plastic. Different mechanisms for serum- and fibronectin-mediated adhesion. Exp Cell Res. 1985;160:287-296.

38. Seiffert D, Schleef RR. Two functionally distinct pools of vitronectin $(\mathrm{Vn})$ in the blood circulation: identification of a heparin-binding competent population of $\mathrm{Vn}$ within platelet alpha-granules. Blood. 1996;88:552-560. 